\title{
EFFECT OF CORD PH AND BASE DEFICIT ON APGAR SCORE, NEED FOR INITIAL VENTILATION AND ENCEPHALOPATHY IN INFANTS $\geq 35$ WEEKS GESTATION, WITH CORD PH<7.0.
}

\author{
S. Ramaiah, H. Sheridan, C. Smith, J.-C. Becher, B. Stenson
}

Neonatology, Royal Infirmary of Edinburgh, Edinburgh, UK

Introduction: Cord $\mathrm{pH}<7.0$ and base deficit (BD) of $\geq-12$ are associated with risk of neonatal encephalopathy. There is limited information about the relationship between degree of acidosis, condition at birth and short term outcome when $\mathrm{pH}<7.0$.

Methods: Cord blood gas data were downloaded from the gas analysers in the delivery suite of the Simpson Centre for Reproductive Health, Edinburgh, between Jan 2005 and May 2010 for infants born $\geq 35$ weeks gestation with $\mathrm{pH}<7.0$. A single sample was included per infant, with the more acidotic specimen selected from paired specimens. Apgar scores at 1 and 5 minutes, need for IPPV during initial stabilisation, neonatal encephalopathy and neonatal mortality were extracted from the clinical records. These were categorised by degree of acidosis.

Results: There were 31151 births during the study. Cord $\mathrm{pH}<7.0$ was documented in 249 infants $\geq 35$ weeks gestation. Data are $\mathrm{n}$, median (interquartile range) and \%.

\begin{tabular}{|l|l|l|l|l|l|l|l||}
\hline $\mathrm{pH}$ & $6.9-7.0$ & $6.8-6.89$ & $<6.8$ & B.D. & $\leq-12$ & -12 to -16 & $>-16$ \\
\hline $\mathrm{n}$ & 196 & 38 & 15 & & 135 & 81 & 33 \\
\hline \hline Apgar 1 & $6(4-8)$ & $4(3-6)$ & $2(1-5)$ & & $6(4-7)$ & $5(3-7)$ & $3(1-5)$ \\
\hline Apgar 5 & $9(8-9)$ & $7(6-9)$ & $4(1-7)$ & & $9(8-9)$ & $9(7-9)$ & $6(4-9)$ \\
\hline IPPV & $56 \%$ & $78 \%$ & $93 \%$ & & $61 \%$ & $56 \%$ & $81 \%$ \\
\hline HIE & $6 \%$ & $37 \%$ & $67 \%$ & & $4 \%$ & $16 \%$ & $52 \%$ \\
\hline Death & 1 & 0 & 3 & & 1 & 3 \\
\hline
\end{tabular}

[table 1]

Conclusions: In infants with cord $\mathrm{pH}<7.0$ there is a dose dependent relationship between degree of acidosis, neurological depression at birth and adverse short term outcome. 